\title{
Д.Б. Жаркимбаева
}

\section{ОНТОЛОГИЧЕСКИЕ ОСНОВАНИЯ ГЕНДЕРНОГО СОЗНАНИЯ КАЗАХОВ В КОНЦЕПЦИИ МУХТАРА АУЭЗОВА «БЕСІГІНДІ ТУЗЕ» - «ЖЕНЩИНА - ВСЕМУ НАЧАЛО»}

\begin{abstract}
Рассмотрень произведения Мухтара Ауэзова как источник изучения гендерных отношений в казахском обществе начала ХХ века. Раскрыты концептуальные взгляды Мухтара Ауэзова на гендерные отношения в традииионном казахском обществе, необходимость формирования гендерного сознания через изменение отношения к женщине, ее положению в семье и обществе. Женщина, по концепции М. Ауэзова, является основной воздействующей силой, формирующей сознание подрастающих поколений. Только изменение положения женщины из зависимого от религиозных догм к свободе волеизъявления, свободе выбора, любви и активной общественной деятельности, позволяющей встать наравне с мужчиной, поможет воспитьвать свободное от патриархальных устоев новое поколение детей.

Ключевые слова: женщина, гендерные отношения, гендерное сознание казашек.
\end{abstract}

Анализ философского содержания художественной литературы, поиск взаимозависимости, взаимопроникновения и единства художественного и философского сознания являются одним из методологических аспектов в развитии теории познания в целом и гендерного сознания в частности.

В философском познании бытия культуры существуют системы ценностных ориентиров, которые на определенном этапе истории приобретают большую значимость. Человеческое общество всегда испытывало острую потребность в произведениях искусства, наполненных интеллектуальным и философским содержанием. Благодаря художественной литературе, аккумулирующей информацию о разных этапах развития общества, отраженных через призму сознания авторов, есть возможность изучать состояние интересующих нас проблем, соединяя прошлое с настоящим. Великий немецкий поэт и драматург Фридрих Шиллер писал: «Приучая человека рассматривать себя в связи со всем прошлым и подготовляя его к выводам в отношении отдаленного будущего, изучение истории стирает границы между рождением и смертью, которые замыкают в себе столь тесные и столь гнетущие границы индивидуальную человеческую жизнь и своей оптической иллюзией удлиняют его краткое существование до бесконечности, делая незаметным переход от индивидуума к роду» [1. С. 623].

В наследии Мухтара Ауэзова отражены его взгляды на особенности национального и общечеловеческого. Отражен его поиск особенностей национального сознания, необходимость его ретрансформации в связи с глобальными изменениями общественных отношений в современную для писателя эпоху. Его произведения отражают именно тот «переход от индивидуума к роду», о котором говорил Фридрих Шиллер, но как переход от индивидуально-национального к роду - общечеловеческому. 
В переломные эпохи усиливается стремление к совершенству, так как происходит переоценка ценностей, и выход из кризиса состоит в восстановлении связей с реальностью бытия прошлого и настоящего с будущим, эти связи устанавливаются в большей степени через систему художественных образов, способствующих формированию новых представлений о жизни.

В начале XX века в Казахстане в условиях смены общественноэкономических отношений, перехода от кочевого образа жизни к оседлому выразителем императивов нарождающегося общества был выдающийся казахский деятель науки и культуры Мухтар Омарханович Ауэзов.

Обладая знаниями о достижениях мирового искусства, а также являясь знатоком духовной культуры казахов, Мухтар Ауэзов сумел создать систему художественных образов, особый их мир, благодаря которому изменились сознание, формы и представления современного ему общества.

Его современник, ученый и общественный деятель Алаш-Орды Халел Досмухамедов писал: «Существование этноса, его дальнейший расцвет связаны напрямую с духовной жизнью народа, его устным творчеством» [2. С. 89]. Формирование новых традиций, выработка новых ценностных ориентиров в социальных отношениях, в том числе и создание национальной модели гендерных отношений, в суверенном Казахстане представляются нам невозможными без освоения основных художественного образов и тем фольклорных и авторских произведений.

В нашем исследовании мы обратились к такому уникальному явлению, созданному Мухтаром Ауэзовым, как ауэзовские женщины. Алексей Пантиелев, переводчик произведений Мухтара Ауэзова, писал: «Мне кажется, давно пора присмотреться к незаурядному художественному явлению, которое по праву может быть названо так: Ауэзовские женщины. Ауэзов видел женщину не по-толстовски и не по-тургеневски. Женские судьбы у него совершенно оригинальны, и это, прежде всего, социальные судьбы...» [3. С. 13-14].

В сочинениях Ауэзова представлена галерея образов, которые ярко демонстрируют не только разнообразие женских судеб, но и неповторимость их сущностно-субстанциональных особенностей. Маленькая храбрая Бекей в повести «Лихая година», несчастная Алуа в романе «Племя младое» женщины, которых запоминаешь навек. Особые чувства вызывают у читателя судьба гордой девочки Газизы и ее бабушки, женщины-аксакала, из рассказа «Сиротская доля». Образ «Красавицы в трауре» запечатлевается в сознании читателя как человек переломного периода истории. Властная своенравная жена и любовница Сотня Верблюжат. Мудрая мать Улжан. Добрая бабушка Зере. Воплощение чистой любви Тогжан из эпопеи об Абае.

Турсун Журтбаев, исследуя мир ауэзовских женщин, писал, что женская тема в казахской литературе была одной из острых, и молодой Ауэзов, так же как и другие его современники (Ахмет Байтурсынов, Миржакып Дулатов, Магжан Жумабаев), увидел свое предназначение «в создании новых ценностных ориентиров, изменение взгляда на положение женщины в обществе» [4. C. 5].

Рассмотрение системы женских образов в творческом наследии Мухтара Ауэзова является для нас актуальным как объект гендерного исследования, поскольку через отраженные в художественных произведениях и публици- 
стических работах образы женщин и отношение к ним есть возможность исследовать гендерные отношения и гендерное сознания казахов начала прошлого века.

Взгляды и идеи М. Ауэзова во многом перекликаются с основными идеями философской и художественной мысли мировой культуры. Ученый Р.Г. Яновский в работе «Женщины и общество: социально-политический аспект» пишет: «Современная концепция человека, принципы и критерии гражданского общества, приоритеты общего согласия и мира выдвигают на передний план проблему свободы женщины, ее разностороннего развития» [5. С. 83].

Личность женщины становится одним из показателей уровня культурного и духовно-нравственного развития общества. Вполне закономерно в связи с этим, что содержание творческого наследия М. Ауэзова, в частности, женских образов и их роль в создании модели гендерных отношений свое начало берут в его публицистике. Мы сочли целесообразным привести здесь цитаты из статьи двадцатилетнего семинариста «Женщина - всему начало», ибо в нейх заложены, как мы указали выше, основные концепты творческого наследия Мухтара Ауэзова в отношении сущностной и общественной роли женщины.

«В то время как мужчина был занят охотой и самим собой, женщина занималась воспитанием детей, строила своё гнездо, основывала свой семейный коллектив. <...> У человека есть две дороги - одна - дорога жить для себя, для своего существования, другая - осознанная жизнь для человечества. <...> По второму пути идут те, кто беспокоится о благополучии всех людей, старается принести как можно больше пользы окружающим. Эту дорогу выбирают благородные, сильные духом личности. Так, что же в нашем окружении, в нашей среде может иметь наибольшее влияние на нас? <...> Человеческое дитя может чему-либо научиться, только если он крепко любит, очень привязан к человеку. Все то, что он увидит в родном близком человеке, будет заложено и в нем самом. Тогда спросим себя, кого любит младенец в первые месяцы своей жизни больше всех? Мать. Если так, то все привычки и взгляды мы перенимаем не от отца, каким бы просвещенным он ни был, а от женщины. <...> Но может ли женщина, мир которой ограничен очагом, домашними хлопотами да сплетнями, которая слышать не слышала о таких словах, как справедливость, благородство, любовь, взрастить достойное дитя? И где бы он потом ни учился, в какой бы среде ни вращался, первые уроки матери останутся в нем навсегда.

Таким образом, выходит, что от положения женщины напрямую зависит состояние общества. <...> И первый шаг к такому перерождению - облегчить положение женщины, сделать ее свободной и счастливой» [6. С. 46-48].

Он писал: «По существу, эту статью мы писали вместе с Турашем (Турашем звали сына Абая Кунанбаева, казахского мыслителя, Турагула). Основная идея была его, я же просто развил его мысль. Подписи под статьей мы не ставили, и потому, то ли Сабит Донентаев, то ли Алимбеков, подписав статью "Семинарист Ауэзов", сдали ее в набор» [7. С. 32]. Данный факт говорит о том, что за изменение отношения к женщине выступали видные обществвенные деятели, с которыми сотрудничал М. Ауэзов. 
Главная ценность этой статьи, на наш взгляд, в том, что в ней отражено этнонациональное отношение к женщине, гендерное сознание. Необходимость изменения отношения к ней и ее месту в обществе указана как основополагающий постулат культурного развития казахского общества. Выражена авторская позиция, в которой он выводит свою концепцию цивилизационного развития: свободное, счастливое положение женщины в обществе - залог социокультурного развития казахского общества в целом. В небольшой статье будущий писатель, как гениальный провидец, в поисках путей возрождения нации дает психологическую атмосферу, в которой формируется национальный характер, а также пишет о возможных последствиях такого отношения к женщине. Выдвинутую автором культурфилософскую концепцию "Бесігіңді түзе" можно рассматривать как национальную программу развития казахстанского общества, не утратившую своей актуальности и по сей день.

В статье совсем еще юный автор, говоря о раскрепощении женщины, выдвигает основной постулат: женщина - основа культурного и духовнонравственного развития - и обращается ко всему обществу с целью донести эту мысль до сознания своего народа.

«Дорога жизни», которая проживается во имя человечества, определяется как жизнь женщины-матери во имя человечества. Мать, воспитавшая в сыне или дочери такие человеческие качества, как любовь к людям, стремление к высоким идеалам духовного, желание творить добро, трудиться и посвящать свой труд во имя счастья других, - это осознанная жизнь женщины во имя будущего человечества.

Он вносит в содержание статьи те мысли, которые в устном творчестве казахов содержатся в таких пословицах, как «үяда не корсең, ұшқанда соны ілерсің», - то, что человек видел в семье, то и будет «подцеплять» когда вырастит. Все ценностные ориентиры, морально-этические нормы, установки на будущее каждый получает в семье от матери. Роль одухотворения сердец, воспитания благородства, личностных деятельностных качеств у детей Ауэзов отдает женщине-матери. В его отношении к женщине отражается гендерное сознание казахов. Ауэзов просит: «Пусть вспомнит каждый свое детство». Этой просьбой Мухтар Ауэзов как бы доказывает роль своей матери в его становлении, подтверждая слова, ставшие афоризмом: «У каждого великого человека была великая мать». Не случайно, создавая образ Абая, центральными персонажами, сформировавшими в Абае будущего поэта, раскрывшими в нем гениальность мыслителя и воспитавшими в нем гуманистические взгляды, Мухтар Ауэзов делает женщин.

В простых мыслях молодого семинариста отражено национальное гендерное сознание, в котором заложено глубокое понимание встроенности женского и мужского начал в единую систему воспитания человека, в которой мужское не доминирует над женским или женское не превозносится над мужским. Но рождается человек из чрева матери, и одухотворение личности идет через материнскую любовь. В этой статье Ауэзов отразил казахское традиционное отношение к женщине и ее роли в обществе. У казахов говорят: «әйел бір қолымен бесік тербетсе, екінші қолымен Әлемді тербетеді» «женщина, одной рукой качая колыбель, второй - укачивает Мир (человече- 
ство). Если не будет женщины, не будет и человечества. Материнство - миссия вечной порождающей, животворящей и одухотворяющей сущности женщины. В образе Матери представляется облик «байбише»- женщины самого старшего мужчины в роду.

Байбише ${ }^{1}$ управляла всей семейной жизнью целого рода. Распределяла имущество, возглавляла работы связанные с переездами, заботилась о благополучии молодых семей, регулировала их взаимоотношения. С возрастом ее роль возрастала и закреплялась за ней как безграничная власть над остальными членами рода. Каждый десяток лет добавлял ей новый круг обязанностей, связанный с увеличением числа членов семьи, их внутренними и внешними контактами. Внутренние - это отношения между отдельными семьями детей. Внешние - это их отношения с другими родственниками в рамках одного рода, а также с другими родами, которые были по отношению к их роду «сватами» или соседями. Это родители и все родственники до седьмого колена снох (невесток) и зятей. Таким образом, в круг обязанностей байбише входило общее руководство всей жизнью рода. Это относилось как к материальному обмену, так и к духовному общению. Все контакты были определены древними обычаями, передававшимися из поколения в поколение. Любое изменение в настроении или отношениях людей умная байбише легко считывала и принимала решение, создавая комфортную для каждого психологическую среду. В случае неправильного поведения кого-либо из рода или других байбише была обязана требовать возмещения материального или морального ущерба. Она же исполняла и роль «арбитра» в различных спорах между родственниками. Особая роль у байбише было в отношениях со сватами. Если байбише допускала «ошибку» в этих отношениях, то весь созданный ею «мир» переживал «потрясение», от возможного «недоброго» исхода событий. Таким образом, байбише была ответственна за благополучие, мир, согласованную жизнь и деятельность всего рода. В числе казахских пословиц по поводу роли байбише сохранились такие: «Хан жарлығынан қатын жарлығы күшті» - «Указ женщины влиятельнее указа хана» и «Ханның тілін халқы алар, қатыны алмас» - «Слова хана исполнит народ, но не жена» [8. С. 52].

Круг интересов женщины-казашки, с переходом на оседлость, стал ограничиваться лишь хлопотами одной семьи. Все вопросы стали решать мужчины. Круг общения и интересов женщины сузился. Она не могла высказывать своего мнения в обществе, вольно разъезжать по просторам степи, смело смотреть в глаза чужому мужчине. Женщина-казашка была «связана по рукам и ногам законами адата», изложенными в соответствии с требованиями ислама. В ней потух интерес к жизни, она стала жить затворнической жизнью, зависить от настроения мужа. Мухтар Ауэзов, излагая взгляды Турагула, указывает на причину такого положения женщины и ее отношения к жизни как к безысходному, бесправному заточению, разрушающему ее внутреннюю уверенность в себе, надежду на свободу, счастливое будущее. Указывает и на вытекающее из этого следствие. «Но женщина, связанная по рукам и ногам законами адата, вольно или невольно передает ребенку толь-

\footnotetext{
${ }^{1}$ Позже «байбише» стали назвать старшую жену любого мужчины.
} 
ко то, что есть в ней самой, и эта ноша потом черным камнем ляжет на самое дно души человеческой, и какие бы ты потом университеты не проходил, из тебя будут лезть наружу злословие, корысть, чванливость, зависть» [9. С. 65].

Воля и свобода женщины-номады были укрощены, и даже сами женщины смирились со своим зависимым положением, так как мужчины ее собственной семьи, защищавшие ее честь и достоинство, ее родные братья и дяди, стали относиться к ним как к «женщине», т.е. существу «на ступень ниже мужчины», призывая смириться со своей участью. «И надо ли говорить о том, что по этой причине в нашей среде мало людей с огнем в душе, с чувством высокого долга служения родной земле» [6. С. 46]. «Законы адата», лишившие женщин в казахском обществе права голоса, вместе с ним лишили ее права быть полноценным членом общества. Своенравная вольная казашка, состязавшаяся в силе и ловкости с мужчинами, открыто высказывавшая свое мнение, была теперь «связана по рукам и ногам» мусульманскими законами.

Какое воспитание может получить ребенок у женщины, которая заперта в доме собственным мужем и не имеет возможности распоряжаться своей судьбой?

Обращаясь к казахам, он просит «выправить колыбель» - "Бесігіңд $i$ түзе!". Начни «с воспитания человеческих качеств». Здесь нужно понять, что человеческие качества может привить только мать, к которой самой относятся как к человеку. И первый шаг к такому перерождению - облегчить положение женщины, сделать ее свободной и счастливой. В этих словах звучит необходимость ретрансформаци гендерного сознания казахов, через восстановление симметричных гендерных отношений, когда мужчина и женщина в обществе имели равные права. Под ретрансформацией понимается возрождение номадического гендерного сознания, которое отражало гендерно симметричные социальные отношения в традиционном казахском обществе.

Для казахской традиционной ментальности было чуждо рассматривать женщину в подчиненном положении. Если женщина в исламе после замужества закрывала лицо, то в казахской традиции есть прямо противоположный ему обряд «открывания лица невесты». Это было событие! Новый член семьи - женщина, от которой продолжится дальше род. В ней уже видели будущую мать рода, которая когда-то сможет стать байбише. Обряд «открывания лица невесты» - это знакомство с будущей матерью и воспитателем своих потомков. А для невесты, после благословения ее новой статусной роли, открывался новый мир в лицах, новое пространство, новое время, новая жизнь. Это было почетно. Она входила в дом полноправной хозяйкой. Этот праздник для женщины-казашки был омрачен религиозными нормами мусульманства, когда девушка становилась уже не первой женой своего мужа. Но женщиныказашки так и не закрыли своего лица в отличие от женщин среднеазиатских республик.

Свое отношение к значению роли матери в воспитании и становлении личности Мухтар Ауэзов проявит в романе «Путь Абая». Показав наиболее значимыми для Абая людьми женщин-матерей. Мудрую бабушку Зере, открывшую Абаю светлый мир народной поэзии, и мать Улжан, привившую ему чувство прекрасного, пробудившую в его сердце чувство сострадания и 
участия к простым людям. От бабушки Зере впервые слышит будущий поэт необычную речь, очаровавшую его слух: « ...века скрывает туман ... Кто постиг, что таится в них? ...» [9. С. 21-23]. Это ей, бабушке Зере, лежащей на смертном одре говорит ее внук идущие от сердца слова: «Все лучшее, все чистейшее в сердце моем от тебя, святая мать» [9. С. 25]. Особенностью казахского языка является его гендерный универсализм [10]. В казахском языке нет родов.

Рассмотрение женских образов в творческом наследии Мухтара Ауэзова в философском аспекте - как системы, формирующей сознание подрастающего поколения и национальный характер, концентрирующей в себе все духовно-психологические уровни жизни общества, представляется нам значимым для более глубокого понимания и осмысления этнонационального духовного наследия. Николай Погодин, русский драматург, определил его творчество как подвиг: «Он помог своему народу познать самого себя, а для других народов сделал прекрасное открытие» [6. С. 23].

Мухтар Ауэзов в течение всей творческой жизни, раскрывая прекрасные образы женщин-казашек, не изменил своему постулату: самая важная роль в формировании черт национального единства принадлежит женщине. Многотрудная кочевая жизнь закрепляла за женщиной ответственность за моральный облик своих потомков, формирования единства в семье, роду, народе. «Бірлік қайда болса, еркіндік сонда, Еркіндік қайда болса, елдік сонда»«Там, где есть единство, есть воля, где есть воля - есть народ» [8. С. 54], учит народная мудрость. Эту волю и взаимопонимание, понимание единства мужского и женского начал требует Ауэзов для процветания своего народа. Этот взгляд на особенности номадического бытия и сознания отразил писатель, общественный деятель современного Казахстана, сын великого писателя, Мурат Мухтарович Ауэзов: «Единый и во всех частях своих взаимозависимый, взаимообусловленный мир. <..> Казах не берет, как правило, в дорогу пищу. Берет готовность понять другого в расчете на взаимность. Законы пути» [11. С. 26]. В номадическом мире основная черта женщины и мужчины - это «воля»: «Воля выше свободы! Миг воли дороже долгой мечты о свободе» [11. С. 23]. Описывая жизнь кочевой семьи, он замечает: «Сила - в Жание», т.е. в женщине. Описывает грани ее сильного характера: «Удивительная жизнеспособность. Многим дала жизнь, многим спасла жизнь».

Основываясь на вышеизложенном, можно сделать следующие выводы в отношении бытия традиционного казахского общества, отраженного в гендерном сознании казахов.

Первое. Онтологическим основанием для формирования гендерного сознания казахов является существование на протяжении многих веков в традиционном казахском обществе гендерно симметрических отношений, где женщина наравне с мужчиной была активным участником социальной жизни.

Bmopoe. Изменению гендерных отношений в сторону гендерной асимметрии, где мужчины становятся «выше», а женщины занимают подчиненное положение, повлияло постепенное доминирование исламского сознания.

Tpeтье. Социальная активность женщины положительно влияет на исполнение ею своей субстанциональной роли матери. Женщина, живущая полноценной, свободной и счастливой жизнью, имеет большую возможность 
воспитать в детях такие качества, как справедливость, честность, благородство, служение роду, человечеству.

Четвертое. Жизнь женщины, активно участвующей в политической и других сферах общественной жизни и при этом воспитывающей собственных детей, признается и оценивается как созидательная деятельность во имя человечества.

Принципиальное отношение к женщине актуально и ныне, в эпоху становления независимого государства, в котором возрождаются утерянные под влиянием иных культур духовно-нравственные ценности исконной казахской культуры, восстанавливаются хранившиеся на бессознательном уровне законы гендерных отношений между мужчинами и женщинами, свободными от религиозного фанатизма.

Для активизации политической деятельности женщин в современном обществе и выхода их на социальную арену в качестве активных деятелей необходима ретрансформация гендерного сознания казахстанского общества, что позволит для развития общества использовать весь потенциал человеческих ресурсов. Для Казахстана третьего тысячелетия важнейшей остается проблема слабого участия женщин в политической жизни государства. Установление гендерно симметричных отношений, основанных на равном участии женщин и мужчин в социально-политической и культурной сферах, является залогом устойчивого цивилизационного развития казахстанского общества.

Президент РК Нурсултан Назарбаев одним из факторов демократизации государства называет активизацию экономической роли женщины в жизни общества, вовлечение ее в процесс управления на всех уровнях власти. Пора раз и навсегда забыть о восприятии женщин как слабого, неполноценного пола, оправдывающем ее социальное неравенство.

\section{Литература}

1. Шиллер Ф. ПСС. М.: Художественная литература, 1981. Т. 1. 638 с.

2. М.О. Ауэзов в воспоминаниях современников. Алма-Ата: Жазушы, 1972.359 с.

3. Ауэзов М. Племя младое. Алма-Ата: Жазушы, 1979. С. 13-14.

4. Журтбаев T. «Начни с колыбели». Алматы: Жазушы, 1997. С. 5.

5. Яновский Р.Г. Женщины и общество: социально-политический аспект // Социальные исследования. 1998. № 5. С. 83.

6. Мұқтар Әуезов. Шығармалар. 50 томдық толық жинағы. Бірінші том. Алматы: Ғылым. 1997. № 46-48 б.

7. Летопись жизни и творчества М. Ауэзова. Алматы: Ғылым. С. 32.

8. Қазақтың мақал мәтелдері. Алматы: Ата мұра. 2013. С. 52-54 [10].

9. Ауэзов М. Путь Абая. Алматы: Жазушы, 1982. С. 65.

10. Жаркимбаева Д.Б. Поиск онтологических смыслов: номадический универсализм человека // Гендерные исследования в гуманитарных науках. Новосибирск, 2012.

11. Ауэзов M.M. Времен связующая нить. Алматы: ИД «Жибек жолы», 2016. 758 с.

Dana B. Zharkimbayeva. Shakarim State University of the City of Semey (Republic of Kazakhstan)

E-mail: dana63mail@mail.ru

DOI: $10.17223 / 1998863 \mathrm{X} / 39 / 18$

ONTOLOGICAL FOUNDATIONS OF THE GENDER CONSCIOUSNESS OF THE КАZAКН IN THE CONCEPT OF MUКНTARA AUEZOVA "БЕСІГІНДI TYЗЕ" - "А WOMAN IS EVERYTHING STARTED" 
Key words: woman, gender relations, gender consciousness of Kazakhs

The article reviews Mukhtar Auezov's works as a source of studying gender relations in the Kazakh society of the early 20th century. The conceptual views of Mukhtar Auezov on gender relations in traditional Kazakh society, the need for the formation of gender consciousness through changing attitudes towards women in their position in the family and society are revealed. A woman according to the concept of M. Auezov is the main influencing force that shapes the consciousness of the younger generations. Only a change in the position of a woman from a person dependent on religious dogmas to freedom of expression of will, freedom of choice, love and active social activities that allows him to become equal with a man will allow the new generation of children free from patriarchal attitudes.

The article reviews Mukhtar Auezov's works as a source of studying gender relations in the Kazakh society of the early 20th century. The conceptual views of Mukhtar Auezov on gender relations in traditional Kazakh society, the need for the formation of gender consciousness through changing attitudes towards women in their position in the family and society are revealed. The concept of "woman - everything began" sounds like a call for the liberation of women from the stereotypes of female defectiveness. The personality of the woman is the most important factor of the cultural and spiritual and moral development of society, which allows to form the consciousness of future generations of children.

Through the attitude of the Kazakh intelligentsia to the position of women, an understanding is revealed of the need for retransmission of gender consciousness and gender relations, which are introduced from cultural religious stereotypes of other societies. The idea of changing the national gender relations is based on the understanding of the change in the gender psychology of the woman herself, reflected in the gender consciousness.

Relations based on spiritual and moral principles, where a woman in a society takes a place next to a man, and not only in a narrow circle of the family hearth that is burdened with nothing but routine, will expand her horizons and inspire her to devote her life to the cultural development of the society and its spiritual growth. The concept of M. Auezov "Woman - everything began" does not lose its relevance even in the modern period of state development. The ideas put forward by the thinker can be viewed as a national program for the development of Kazakhstan's society, in which an important role is assigned to activating women in public and political life and creating conditions for their equal participation at all levels of the state administration system.

\section{References}

1. Shiller, F. (1981) Polnoe sobraniye sochineniy [Complete Works]. Vol. 1. Moscow: Khudozhestvennaya literature.

2. M.O. (1972) Auezov v vospominaniyakh sovremennikov [Auezov in the Memoirs of His Contemporaries]. Alma-Ata: Zhazushy.

3. Auezov, M. (1979) Plemya mladoe [The Tribe of the Young]. Alma-Ata: Zhazushy. pp. 13-14.

4. Zhurtbaev, T. (1997) Nachni s kolybeli [Start with the cradle]. Almaty: Zhazushy. pp. 5.

5. Yanovskiy, R.G. (1998) Zhenshchiny i obshchestvo: sotsial'no-politicheskiy aspekt []. Sotsial'nye issledovaniya - Social Studies. 5. pp. 83.

6. Auezov, M. (1997) Shyzarmalar. 50 tomdyқ tolyқ zhinazy [Extras. The Complete Collection in 50 vols]. Vol. 1. Almaty: Fylym.

7. Auezova, L.M. (ed.) Letopis' zhizni i tvorchestva M. Auezova [The Chronicle of Life and Work of M. Auezov]. Almaty: Fylym.

8. Kazakhstan. (2013) Қазақ̆tyң maқ̧al motelderi [Kazakh Proverbs]. Almaty: Ata mura. pp. 52-54.

9. Auezov, M. (1982) Put' Abaya [The Way of Abay]. Almaty: Zhazushy.

10. Zharkimbaeva, D.B. (2012) [Search for ontological meanings: nomadic universalism of man]. Gendernye issledovaniya $v$ gumanitarnykh naukakh [Gender Studies in the Humanities]. Proc. of the International Conference. Novosibirsk, 2012.

11. Auezov, M.M. (2016) Vremen svyazuyushchaya nit' [Time Connecting Thread]. Almaty: Zhibek zholy. lmaty: ID «Zhibek zholy». 2916. $758 \mathrm{~s}$. 